\title{
CASE STUDY REGARDING MEASUREMENTS IMPLEMENTED WITH THE REPAIR ENTRY A HYDROGREGATE CAMPELA WITH VIBRO EXPERT DIAGNOSIS SYSTEM
}

\author{
Ionel Rusa1, Cornel Marin². Marius Baidoc 3 \\ 1,2 VALAHIA University of Târgoviște, FIMM, Str. Aleea Sinaia Nr.13, Targoviste \\ ${ }^{3}$ S.C. Vibro System S.R.L. \\ ionelrusa@gmail.com , marin cor@yahoo.com, info@vibrosystem.ro
}

\begin{abstract}
Permanent knowledge of the technical state of rotating turbines, intelligent planning of interventions according to the evolution of vibrations parameters, identification and correction of mounting errors, are the important objectives of proactive maintenance that the operating engineer must pursue for avoidance disruptions or definitive decommissioning. The purpose of this paper is to present a case study on the vibrations diagnosis of hydro-aggregate CAMPELA HA1 - CHE Dubasari/12 MW /120 RPM. The Vibro Expert diagnosis system mounted on CAPMELA is designed to measure, monitor, diagnose, predict and analyze the main technical and functional parameters of the hydro-aggregate in order to exploit it in maximum safety.
\end{abstract}

Keywords: Hydro-Aggregate, Vibration Measurement, Vibro Expert Diagnosis System, Proactive Maintenance

\section{Introduction}

In the current economic context where technology and work efficiency play a crucial role, proactive maintenance activities has become a necessity, even if it involves the initial high costs of implementation. The main advantages of proactive maintenance activities are: knowledge of the current technical state of equipment, repairs planning based on knowledge of the technical time-behavior of hydroaggregate unit operation, avoid operation under unsuitable parameters until they are destroyed, detecting and correcting errors in the installation or repair, repair costs of unit operation much lower.

\section{Data Acquisition And International Standards ISO 7919-1/5, 10816- 1/5 10817-1}

\subsection{The Professional VIBRO EXPERT Diagnosis System}

The professional VIBRO EXPERT diagnosis system is produced by Delphin Technology Germany LTD. This is a professional system dedicated to implementing a proactive maintenance program.

The VIBRO EXPERT diagnosis system contain two acquisition modules with 8 channel, six measurement sensors for relative proximity vibration and VIBRASENS accelerometer transducers for vibration measuring.

\subsection{The Integrated Acquisition and VIBRO EXPERT}

The integrated acquisition and VIBRO EXPERT diagnosis system monitors both the absolute vibrations in the bearing area and the relative vibrations of the proximity transducers. The system is also equipped with laser sensors for continuous measurement and registration of the speed of main turbine shafts (Figure 1).

The relative vibrations of the shaft were measured with 8 proximity sensors without SE8 contact. Measurement of the relative vibrations of the shaft was carried out in two directions perpendicular to the 4th sections:

1. LGS Radial Axial Generator Superior Bearing,

2. LGI Lower Generator Bearing,

3. LI Intermediate Bearing,

4. LT Turbine Bearing. 


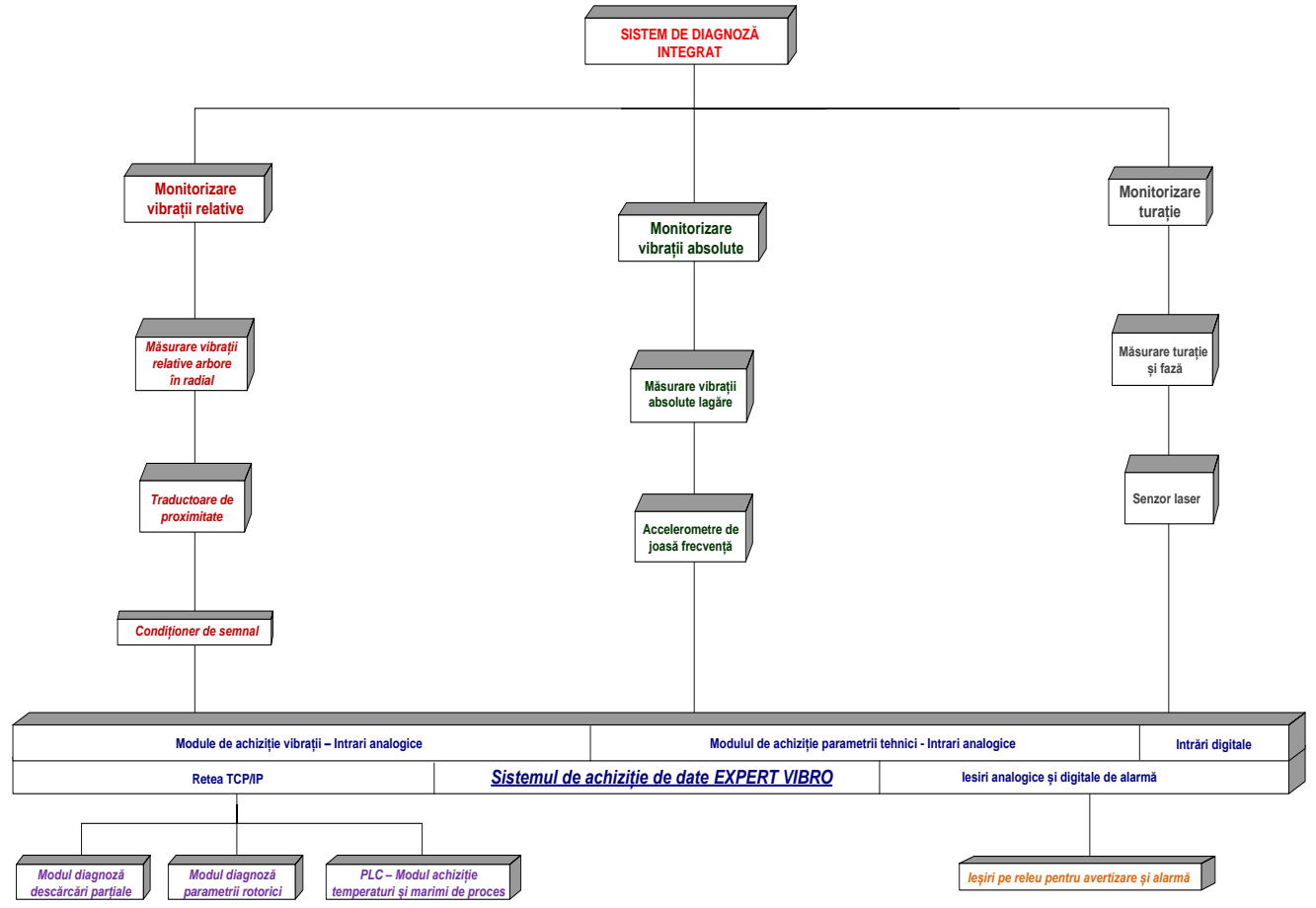

Fig. 1.

The measurements are synchronized by the phase sensor mounted in the machine axis area. (Figure 2)

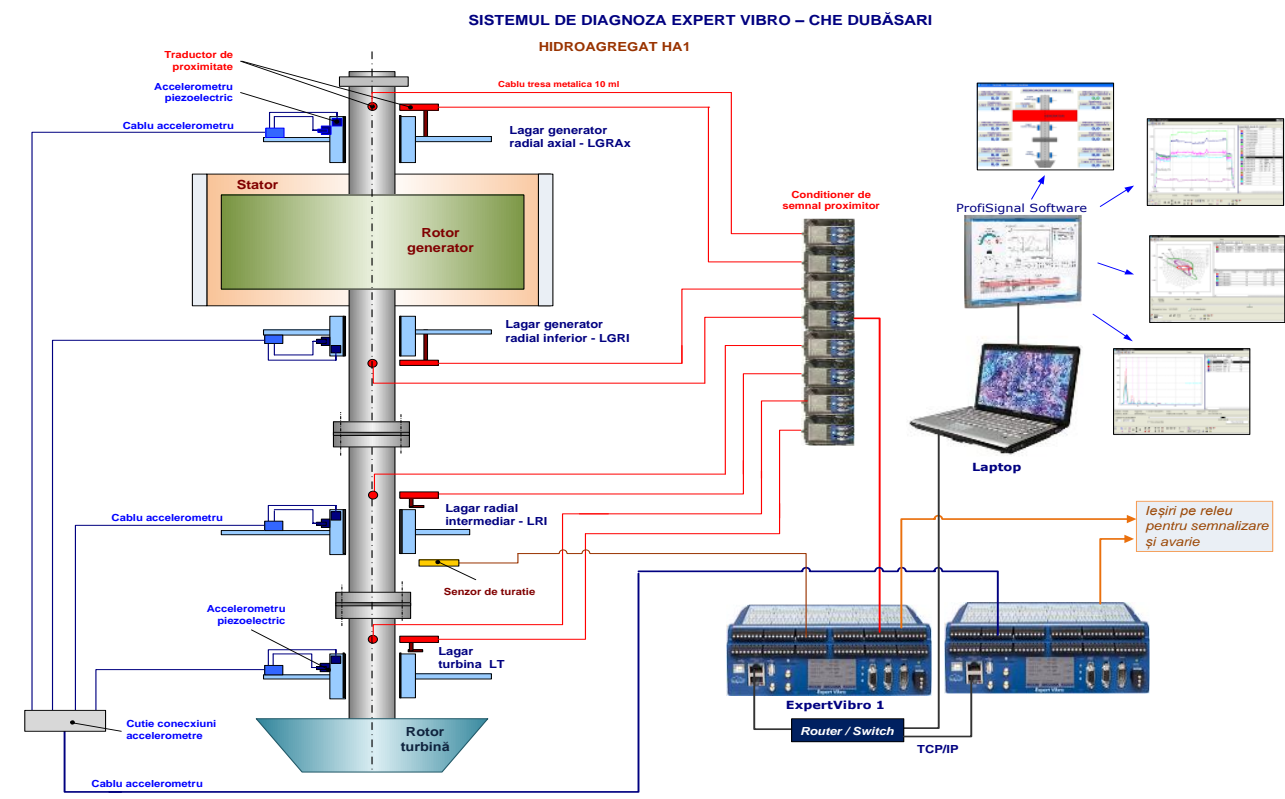

Fig. 2.

\subsection{The Accelerometer and Speed Transducers}

The piezo-ceramic element is subjected to shear and has a sensitivity of $100 / 500 \mathrm{mV} / \mathrm{g} \pm 5 \%$, ICP / IEPE type, AC acceleration output. Technical specifications of VIBRASENS 101.51-9 accelerometer transducer (Figure 3):

- Sensitivity (+/- 5\%): $500 \mathrm{mV} / \mathrm{g}$;

- Measuring range: +/- $10 \mathrm{~g} \mathrm{pk}$;
- Frequency range (+/- 5\%): $0.2-3700 \mathrm{~Hz}$;

- resonant frequency: $16 \mathrm{kHz}$;

- limit overload (shock): +/- $5000 \mathrm{~g} \mathrm{pk;}$

- residual noise [at $1 \mathrm{~Hz} \ldots 25 \mathrm{kHz}$ ]: $25 \mu \mathrm{g} \mathrm{rms}$

- transverse sensitivity [20 Hz, $5 \mathrm{~g}]<5 \%$

- operating temperature limits: -50 to $+120^{\circ} \mathrm{C}$;

- Supply voltage: 5-30 V DC

- Power supply [mA DC]: 2-10 mA;

- connector: M12

- weight 95 grams

- Degree of protection: P65. 


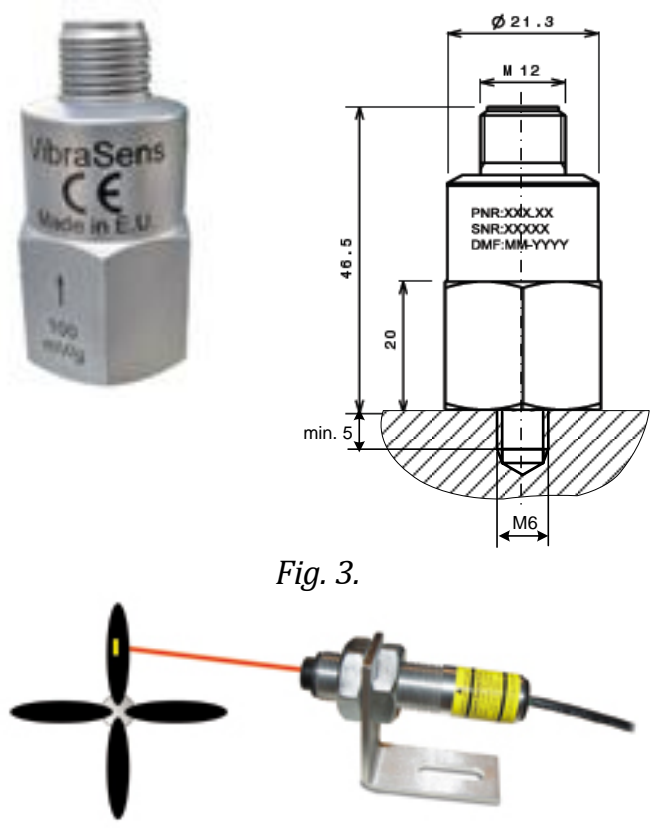

Fig. 4.

The synchronization, speed and phase transducer is a non-contact laser sensor ROLS-W - Monarch Instruments (Figure 4) with technical specifications:

-rotation range 1-250,000 rpm

-Nickel-plated metal housing

-the beam: visible-red

-Distance: $0 \mathrm{~mm}$... $1 \mathrm{~m}$

-24 V DC supply voltage

- 5 V TTL output

\subsection{The Absolute and Relative Vibration Acquisition EXPERT VIBRO System}

The diagnostics and analysis (of vibration) module has the following characteristics:

- the general analysis and tracking analysis (vs. time / vs speed / vs harmonics),

- the spectral analysis (FFT, cepstrum, auto spectrum, phase spectrum)

- the tire analysis, alarm and signaling functions; orbits; time capture; phase analysis facilitates the storage of large data volumes in real time;

Statistical analysis module (mean, median, variant, coherence, kurtosis analysis etc); flexible graphical user interface (2D, 3D, automatic axis adjustment, etc.).

The system interface displays all the measured data and the charts resulting from the data processing.

The VIBRO EXPERT diagnosis system has a database where important data will be stored. This database can be transferred to an external storage medium.
The systems will be equipped with the PROFISIGNAL software for data acquisition, processing and presentation, diagnosis, archiving, etc.

\subsection{The PROFISIGNAL Program for Data Acquisition, Processing, Presentation and Diagnosis}

The PROFISIGNAL program includes two software modules:

\section{A. Module - PROFISIGNAL BASIS}

The basic module acquires, views, monitors, controls, analyzes, stores and exports technical data from sensors: vibrations, airspeed, etc. The basic module is easy to use and for each monitored parameter you can choose the convenient unit of measure. Measured data is purchased and viewed online and analyzed in real time. At the same time, the stored data can be accessed and analyzed over time.

Viewing Processes - With PROFISIGNAL BASIS module you can create charts (pictures, sketches) of monitored equipment, and display parameters can be done analog or digital.

With PROFISIGNAL BASIS module you have options to editing technical reports and process control.

\section{B. Module - PROFISIGNAL VIBRO}

The software is compatible with the hardware part of the system and is designed to measure, monitor, and analyze vibration amplitudes. Vibration measurements can be purchased and viewed online and off-line.

The software allows you to display in $2 \mathrm{D}$ or $3 \mathrm{D}$ several types of measurements such as:

- Global vibration,

- Spectrum frequencies (amplitude depending on frequency),

-Waveform (amplitude based on time),

- The shaft orbit in the bearing (the relative vibration of the spindle in the bearing),

- Bearing state measurements (bearing envelope),

- Phase-speed measurements, etc.

In order to correctly diagnose the operating status of the equipment, the module allows:

-simultaneous display of measured data across multiple channels.

The data will be saved and written in real time (on-line) directly on the hard disk and / or in the memory of the base machine.

- fittings of the order of $2 \ldots 10$ selectable, low pass filter, high pass and band, mediation and signal integration will be available. Operating System Computer: Windows 7, 2000 / XP, etc. 
The program has the ability to create virtual computing channels directly in the basic software or PC software to obtain any vibration or technical parameter you want by mathematical relationships. Simple mathematical relationships can be achieved assemblies, decreases, divisions, multiplications -, $\operatorname{logic}<,>,=$, if, etc. Or complex integrations, derivations, PID, FFT spectral computation, mediation, linearization, timer functions etc.

The vibration characteristics that can be calculated using PROFISIGNAL VIBRO Module are:

- Peak-peak, mean, effective RMS, 0-peak, 0lower,

- Amplitude and main frequency,

- Speed and phase at main amplitude,

- Amplitude and fundamental phase $1 \mathrm{x}$,

- Amplitude and component phase 2 x, 3 x, 4 x etc.

- The maximum value of the vector sum for 2 signals

- The average product for 2 signals,

- Frequency of main amplitude for 3 frequency bands,

- Main amplitude for 3 frequency bands,
- Efficient RMS value for 3 frequency bands, etc.

\section{Technical Conditions of Measurement According to ISO 7919-5 and ISO 10816-5.}

Vibration measurements were performed with proximity sensors for relative vibration measurement in accordance with ISO 7919-5 and with uni-axial accelerometers for absolute vibration measurement in accordance with ISO 10816-5. Vibration measurements were performed on three $\mathrm{X}$, $\mathrm{Y}, \mathrm{Z}$ directions.

The following notations were used to determine the direction of measurement:

-the $\mathbf{X}$ direction is similar to the upstream direction,

-the $\mathbf{Y}$ direction is perpendicular to the upstream line,

-the $\mathbf{Z}$ direction is parallel to the axis of rotation of the machine spindle.

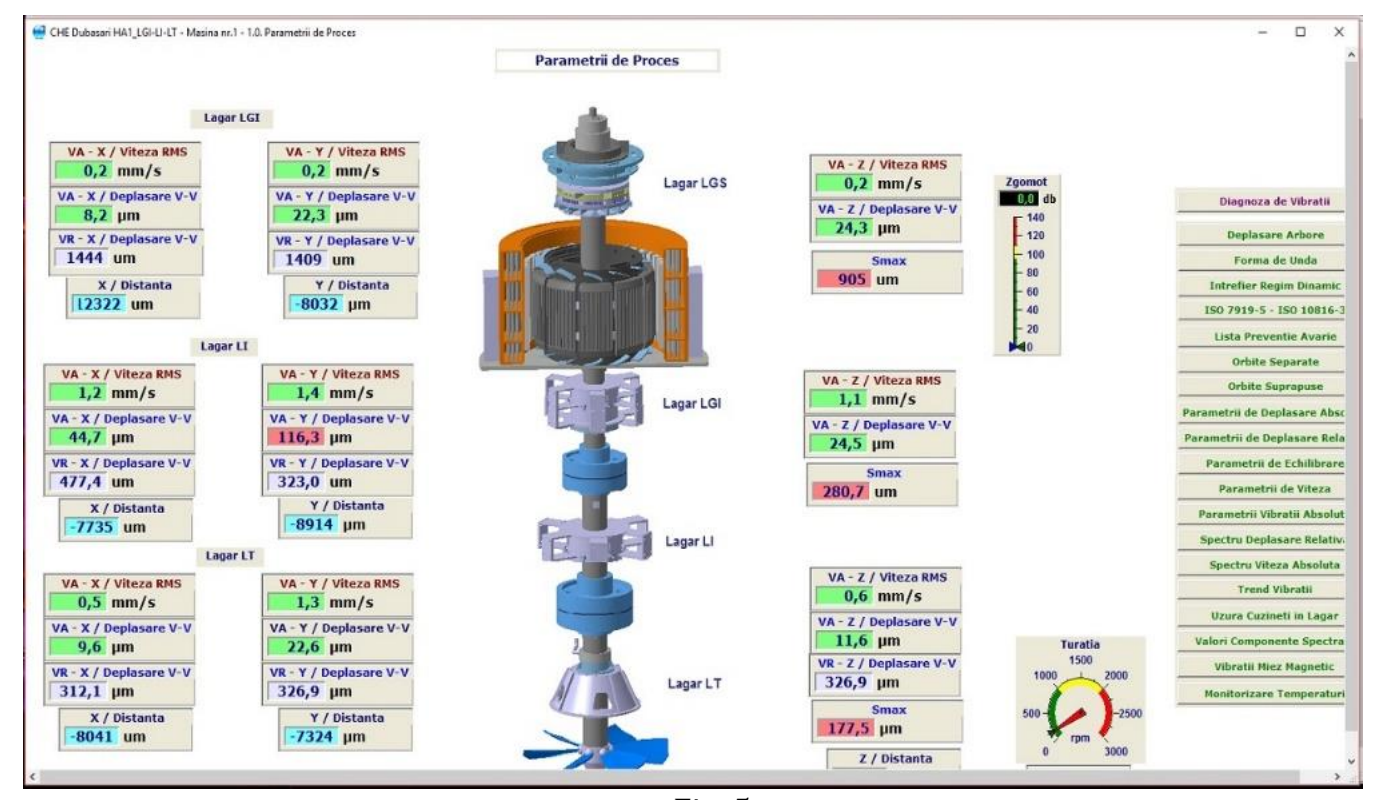

Fig. 5.

Figure 5 show the process parameters of hydroaggregate bearings and X, Y, Z directions on the LGS LGI - LI - LT. The measurements are synchronized by a phase sensor mounted in the machine axis area. The relative vibration of the shaft was measured radially in two X-Y perpendicular directions in the four sections of hydro-aggregate bearings:

1. LGS -Superior Generator Bearing, which is also an Radial Axial Bearing (Figure 6)

2. LGI -Lower Bearing Generator (Figure 7),

3. LI -Intermediate Bearing (Figure 8),

4. LT -Turbine Bearing (Figure 9).
The absolute vibrations of the bearings were carried out with acceleration transducers accelerometers mounted in the three $\mathrm{X}, \mathrm{Y}, \mathrm{Z}$ directions, as follows: 2 radial directional sensors $X$ $\mathrm{Y}$ and one axial Z-axis sensor.

The axial direction sensor is mounted in the $\mathrm{X}$ axis or $\mathrm{Y}$ axis plane, where the vibration amplitude value is higher. ISO $10816-5$ does not specify the admissible vibration value in axial direction $\mathrm{Z}$.

Figures 6-9 show also the positioning of vibration sensors - accelerometers and proximity probes - in the three X, Y, Z directions on the LGS LGI - LI - LT hydro-aggregate bearings. 


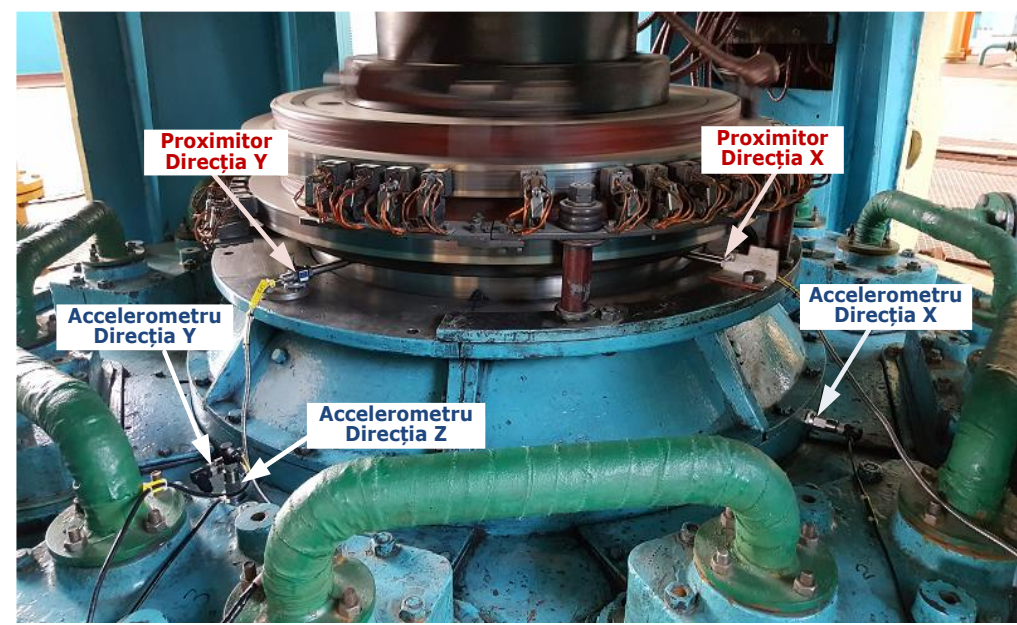

Fig. 6. Sensor positioning on the LGS Superior Generator Bearing

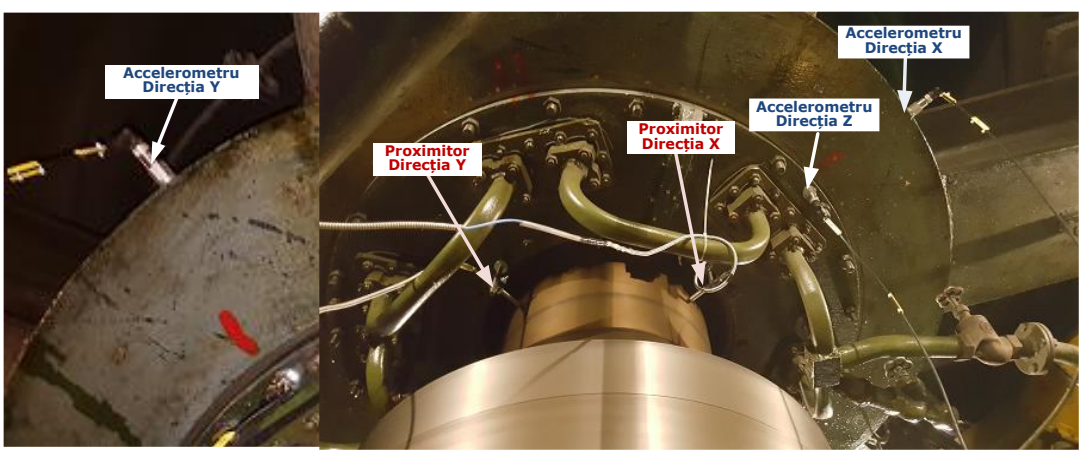

Fig. 7. Sensor positioning on the LGI Lower Generator Bearing
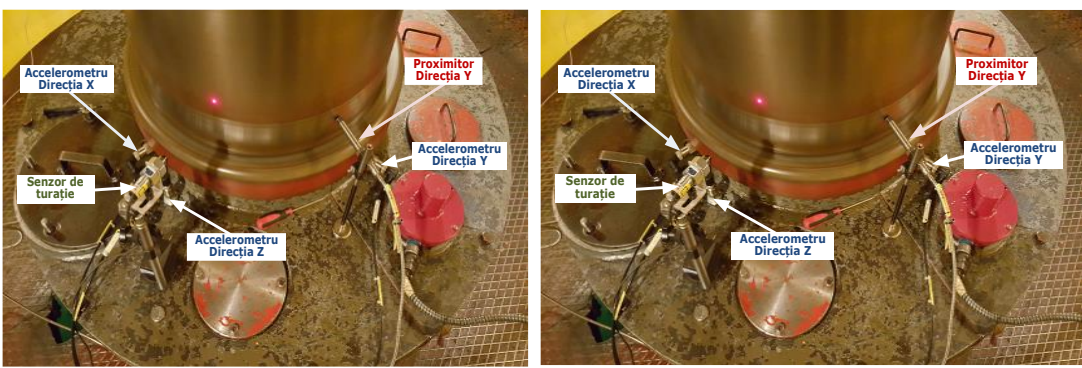

Fig. 8. Sensor positioning on the LI Intermediate Bearing
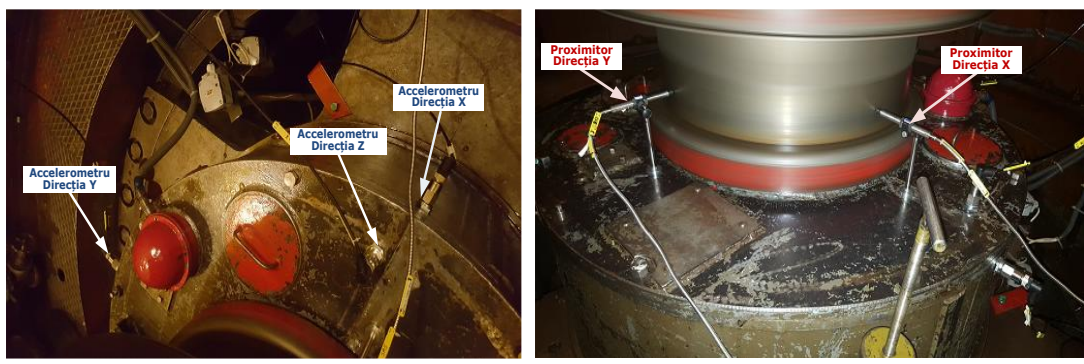

Fig. 9. Sensor positioning on the LT Turbine Bearing

\section{Operating Regimes and Types of Measurements Carried Out}

Vibration measurements were performed on hydroaggregate in the following operating modes:
- At $120 \mathrm{rpm}, 140 \mathrm{rpm}, 150 \mathrm{rpm}$ - without excitement,

- Empty with excitement,

- In charge of 4.8 MW power,

- In charge of 7.2 MW power,

- In charge of 9.6 MW power, 
- In charge of $12 \mathrm{MW}$ power,

With the diagnostics EXPERT VIBRO system, the following technical parameters of global Vibration were monitored:

- Relative vibration of the hydro-aggregate shaft according to ISO 7919-5, - Smax value of the vibration according to ISO 7919-5,

- Absolute bearing vibration according to ISO 10816-5,

- Absolute speed vibration, and vibration of movement

- Shaft speed and vibration phase. -The amplitude of the fundamental vibration the $1 \mathrm{x}$ component and the phase for the determination of the imbalance vector

\section{Experimental Data}

The diagnosis of hydro-aggregate operation was performed in all machine operating regimes described in point 4 by analyzing the relative vibration (displacement and Smax.) and the absolute vibration and speed and vibration movement. Following the vibration measurements, the highest amplitudes of relative vibrations were recorded on the lower generator bearing LGI, and then on the superior generator bearing LGS.

These high amplitudes have been recorded in all hydro-aggregate working regimes, resulting in the Machine's Not Allowed Rating - Global Relative Vibration Level Bulletin No. 1. [8]

The spindle in the superior generator bearing LGS has a deflection that has affected the correct reading of relative vibrations by proximity sensors. To eliminate this large amplitude generated by spindle, correct vibration readings were made from the wave / orbit waveform. - In this respect it is recommended to process the roughness at max. $6.3 \mu \mathrm{m}$ (generator, intermediate and turbine) over an spindle area of min. $40 \mathrm{~mm}$ in the proximity probe read area corresponding to each bearing, for subsequent accurate vibration measurements (after machine repair). This spindle defect is highlighted by the LGS bearing orbit measurement.

Absolute vibration diagnosis, vibration velocity amplitudes, fit the machine to the rating of $9.6 \mathrm{MW}$, and for the other 4,8-7,2-12 MW ratings, the rating is Good. Global Speed Absolute Absolute Rate Bulletin no. 2.[9]

From Vibration Movement Records, the machine qualifies as Not Allowed for All Load Modes and Admitted under Surveillance for Extreme Nervous Mode. Global Absolute Movement Level Bulletin No. 3 .[10]

The vibration measurements performed on the hydro-aggregate bearings were analyzed for the following three working regimes:
A. Regime: Blank idle at: $120 \mathrm{rpm}, 140 \mathrm{rpm}$, 150 rpm, 165 rpm

At the $120 \mathrm{rpm}$ speed of the hydro-agregate there was an intermittent friction of the generator, the orbit shown in Figure A1 and Figure A6 highlights this phenomenon. In this respect, it is recommended to check the generator rotor, especially in the LGS and excitation area. On idle speeds at $120 \ldots 165 \mathrm{rpm}$, the relative and absolute vibrations were lower than in the load regimes.

B. Regime: Raise and lower the engine speed to the unplanned idle mode

Upon rising and lowering speed to $150 \mathrm{rpm}$, the vibration amplitudes relative to the generator bearings LGS - LGI significantly increased LGS - 610 $\mu \mathrm{m}$ V-V (Peak-Peak) / X direction, respectively LGI $889 \mu \mathrm{m} V-\mathrm{V}$ (Peak-Peak) / X direction, exceeding the allowable limit of standard ISO 7919-5 for machines with a speed of $150 \mathrm{rpm}$ - admissible limit of $525 \mu \mathrm{m}$ VV.

Hence, the machine operates with high vibrations since the unplanned idle mode. See Annex 1 Figure A.25 ... A.27 -Global Relative Vibration Level Bulletin No. 1. [8]

Absolute vibration analysis for the same work mode, idling speed - idling - descent speed was performed in two ways, namely: vibration speed and dpv of absolute displacement. In the case of the vibration velocity analysis, it can be seen that the highest vibration velocity was recorded on the LI / Y direction - $1.37 \mathrm{~mm} / \mathrm{s}$ RMS but this value is acceptable, Good rating. See Annex 1, Figure A.46 ... A.47 - Global Speed Absolute Absolute Rate Bulletin No.2. [9]

When analyzing the vibration displacement, the highest value was also recorded on the intermediate bearing LI / Y direction, $67 \mu \mathrm{m} \mathrm{V-V}$ (Peak-Peak), this value making the machine qualify as Admitted under supervision rating. See Annex 1, Figure A.57 ... A.58 - Global Absolute Movement Level Bulletin No. $3[10]$

C. Regime: Comparative analysis between the unplanned idle mode and the load

C1.Relative vibration analysis

The amplitudes of relative vibrations recorded on the lower bearing LGI and the intermediate bearing LI increased significantly with the excited car and the load at all measured modes virtually doubled compared to the uncharged machine mode. See Annex 1 - Figure A.28 ... A.29. [11]

The magnitude of the vibration amplitudes relative to the lower bearing LGI $1462 \mu \mathrm{m} \mathrm{V}-\mathrm{V}$ (Peak-Peak) (7.2 MW) nearly exceeded three times the admissible vibration value of $525 \mu \mathrm{m} \mathrm{V-V}$ (PeakPeak).

By analyzing the FFT frequency spectra, this increase may be due to several causes, namely nonuniform air gap, which leads to an electrical imbalance corroborated with bearing faults and 
shaft disengagement. See Annex 1 - Figure A.37 ... A.41.

For this type of defect, it is recommended, in the first phase, to check for weaknesses in the LGI bearing (bearing wear, cracks, etc.), then the air gap and the de-stressing of the shafts. The orbit registered at this LGI camp highlights this phenomenon. See Annex 1 - Figure A.6 ... A.17. [11]

From the LGI inferior generator orbit analysis, it can be noticed that when the machine is at $4.8 \mathrm{MW}$ ... $12 \mathrm{MW}$, it flattens slightly, leading to bearing loading and occurrence in the frequency spectrum of the upper $2 \mathrm{x}-4 \mathrm{x}$ components. See Annex 1 - Figure A.39. [11]

After these checks, it is advisable to perform a new set of vibration measurements in which to analyze the mechanical imbalance vector. If it exceeds the allowable value specified in ISO 1940, it is recommended to perform the dynamic balancing of the generator rotor. The same conclusions can be drawn to the Smax parameter analysis. See Global Relative Vibration Level Bulletin No. 1 [8]

In most cases, the phenomenon is inversely, i.e. when it's empty, the vibration level is higher than the load regime, and this happens when the bearings are admissible, the alignment of the trees is correct and the residual mechanical imbalance is admissible. This phenomenon is explained as follows: When the electromagnetic field occurs (machine load mode) a field in the field of the generator rotor takes place with the increase of the forces in the generator bearings. If the bearing has excessive weaknesses or wear, vibration amplitudes increase significantly, which results in the bearing being loaded.

Another phenomenon can be observed on the turbine bearing at relative vibration measurements, namely: X-direction displacement shows significant increases by short-term amplitude pulses over 1000 $\mu \mathrm{m} V-\mathrm{V}$ (Peak-Peak) when passing the machine from 7.2 MW to 9, 6 MW. See Annex 1 - Figure A.30 ... A.31. [11]

These impulses can be generated by machine instability in the $\mathrm{X}$ direction (upstream downstream) in conjunction with hydraulic forces and cavitations phenomenon. This phenomenon is also emphasized by the analysis of the orbits and frequency spectra recorded on the turbine bearing. See Annex 1 - Figure A.32 ... A.36[11]

\section{C2. Absolute vibration analysis}

When analyzing the absolute vibrations, the same phenomenon can be emphasized: significant increase of the vibrations with the car in charge compared to the idling regime.

This increase occurs both in terms of vibration and travel. See Annex 1 - Figure A.42 ... A.45. - LGS speed, Figure A.48 ... A.49. - LGI_LI_LT displacement, Figure A.59 ... A.60. [11] The absolute vibration frequencies performed on the hydro-agregate bearings and on the excitation body highlight the following aspects:

- The absolute highest vibration found in the spectrum recorded on the excitation body is due to the $7 \mathrm{x}=17.5 \mathrm{~Hz}$ component $(7 \mathrm{x} 2.5 \mathrm{~Hz}=17.5 \mathrm{~Hz}$, where $2.5 \mathrm{~Hz}$ is the rotation speed of the machine $150 \mathrm{rpm} / \neg \quad 60=2.5 \mathrm{~Hz}$ ). This vibration is due to a weakening in the area of the generator or its foundation. $\neg$ In this respect, it is advisable to check the generator bearings, their stiffening elements, the upper and lower star and including the generator base.

- The value of the $7 x$ component changes depending on the machine mode. At $150 \mathrm{rpm}$, the amplitude of the velocity was $3.84 \mathrm{~mm} / \mathrm{s}$ and at 165 rpm the value dropped to $2.17 \mathrm{~mm} / \mathrm{s}$. Annex 1 Figure A.50 ... A51. [11]

Highest velocity values were recorded at idle speed of $140 \mathrm{rpm}$ - above $25 \mathrm{~mm} / \mathrm{s}$. Annex 1 Figure A.42. Practically at the $135-140 \mathrm{rpm}$ speed of the hydro-generator, the weakening is excited to the maximum - possibly the resonance input of a component of the generator or foundation. In charge, the vibration value varies depending on the size of the load at $12 \mathrm{MW}$, the speed value is $7.08 \mathrm{~mm} / \mathrm{s}$. Annex 1 - Figure A.52. [11]

- Analysis of FFT spectra on the LGI camp results in higher order spectral components with admissible level in which the $7 \mathrm{x}$ component is also found. See Annex 1 - Figure A.53 [11].

The overall vibration speed is relatively small, meaning that the bearing is rigid given that the relative displacements have the highest values on the machine. These large displacements of the spindle are damped by the oil film and possibly by excessive wear of the bearing or the weakening of the bearing components to the carcass, where the absolute vibration level is permissible. The highest vibration speed values are found on the intermediate bearing LI, and the FFT spectrum recorded on this bearing indicates excessive games, top-of-the-line components, including 7x approx. $1.1 \mathrm{~mm} / \mathrm{s}$. See Annex 1 - Figure A.54. [11]

- Speed values recorded $\mathrm{o} \neg \mathrm{n}$ the turbine bearing give the Good rating and the frequency spectrum indicates admissible bearings due to the hydraulic forces. See Annex 1 - Figure A.55. [11]

- The speed orbit is shown in Figure A.56 where the speed compared to the three bearings of the machine can be observed.

- Absolute displacement frequency spectra indicate the same types of defects, with the exception that they highlight the low frequency spectral components and the global values given by this parameter place the machine at a non-allowable load rating. See Annex 1 - Figure A.61 ... 63. [11]

- The absolute displacement orbit is shown in figure A.64 where the motion of the bearings in space on the X-Y directions can be observed. From 
here it can be concluded that the hydro-agregate bearings have a more pronounced displacement in the $\mathrm{X}$ direction.

\section{Conclusions and Recommendations}

For the quality of the hydro-aggregate repair, the following are recommended:

- Verification of games / tolerances in the hydroaggregate bearings, especially in the LGI and LGS bearings and if they correspond to the machine repair card;

- Verification of weaknesses in LGI inferior generator bearing - cracks or exfoliations in the cuff, loosening of pills or bolts, etc.;

- Practically checking the rigidity of the bearing. It is recommended that the same checks be applied to the axial radial bearing LGS - LI - LT;

- Checking the air gap, due to the significant increase in relative vibration amplitudes and absolute displacement on the LGI and LI bearing when the hydro-aggregate is in charge;

- Achievement of shaft alignment / generator shaft - intermediate shaft - turbine shaft / according to the hydro-aggregate mounting documentation. For this operation high precision digital tilt meters, proximity sensors or comparator watches can be used;

- Making new vibration measurements for the calculation of the permissible deck of the generator rotor. If this does not correspond, the dynamic rotor balancing is recommended.

Tolerances for vertical hydro-aggregates when manufacturer's tolerances are not available are shown below in Table 1. Always consult the hydrogenerator manufacturer if possible. These tolerances are recommended to be used when manufacturer's tolerances are not available. This table is based on the recommendations of Bill Duncan author [12] .

\begin{tabular}{|l|l|}
\hline \multicolumn{1}{|c|}{ Type of measurement Tolerance } & Recommendation: \\
\hline Stator switch & $\pm 5 \%$ of rated design air gap \\
\hline $\begin{array}{l}\text { Stator concentricity (depending on turbine } \\
\text { bearing) }\end{array}$ & $\pm 5 \%$ of rated design air gap \\
\hline $\begin{array}{l}\text { Concentricity of the upper generator LGS } \\
\text { depending on the LGI lower bearing and the LT } \\
\text { turbine bearing) }\end{array}$ & $20 \%$ of the bearing diameter of the bearing \\
\hline $\begin{array}{l}\text { Concentricity of the lower LGI generator } \\
\text { (depending on the LGS upper bearing and the LT } \\
\text { turbine bearing) }\end{array}$ & $20 \%$ of the bearing diameter \\
\hline $\begin{array}{l}\text { Concentricity of sealing ring (depending on LT } \\
\text { turbine bearing) }\end{array}$ & $10 \%$ of diameter seal of sealing ring \\
\hline Stator circularity & $\pm 5 \%$ of nominal design air gap \\
\hline Rotor circularity & $\pm 5 \%$ of rated design air gap \\
\hline Rotor Vertical (depending on generator shaft) & $\pm 5 \%$ of rated design air gap \\
\hline Shaft Linearness & $\begin{array}{l}<0.076 \text { mm - No reading point shall have a deviation } \\
\text { greater than 0,076 mm from a vertical straight line } \\
\text { linking the reading point higher than the lower one }\end{array}$ \\
\hline Static shaft deviation & $\begin{array}{l}<0.05 \text { mm multiplied by the shaft length in the axial } \\
\text { bearing to the deviation measurement point divided } \\
\text { by the rotor diameter in the axial bearing section }\end{array}$ \\
\hline $\begin{array}{l}\text { Deviation of the center of the shaft } \\
\text { length from the upper reading position to the lower } \\
\text { reading position }\end{array}$ \\
\hline
\end{tabular}

\section{References}

[1] Introducere în vibrații - Ref.Doc.MI 119 - Notă tehnică / Mobil Industrial - Pitești (2013)

[2] Mentenanța utilajelor dinamice vol . 1 - Mobil Industrial AG - Pitești (2011)

[3] Vibration Calibration Technique and basics of Vibration Measurement - Torben R. Licht Singapore 2011
[4] An Introduction to Vibration Analysis Theory and Practice

[5] Automated machinery maintenance - Bill Powel, Tony Burnet

[6] Bearing vibration analysis - Connected Technology Center - Training modules

[7] Ghidul analistului de vibrații - Costin Ciprian Ilie

[8] S.C. VIBRO SYSTEM S.R.L. www.vibrosystem.ro Global Relative Vibration Level Bulletin No. 1. 
Case Study Regarding Measurements Implemented with the Repair Entry a Hydrogregate Campela with Vibro Expert Diagnosis System

[9] S.C. VIBRO SYSTEM S.R.L. www.vibrosystem.ro Global Speed Absolute Absolute Rate Bulletin no. 2.

[10] S.C. VIBRO SYSTEM S.R.L. www.vibrosystem.ro Global Absolute Movement Level Bulletin No. 3
[11] S.C. VIBRO SYSTEM S.R.L. www.vibrosystem.ro - MEASUREMENT TECHNIC REPORT sept 2016ANNEXE 1

[12] Bill Duncan - "Bureau of Reclamation Plumb and Alignment Standards for Vertical Shaft Hydro-units".

Annexe 1: Measurement Technic Report (Sample)

September 2016

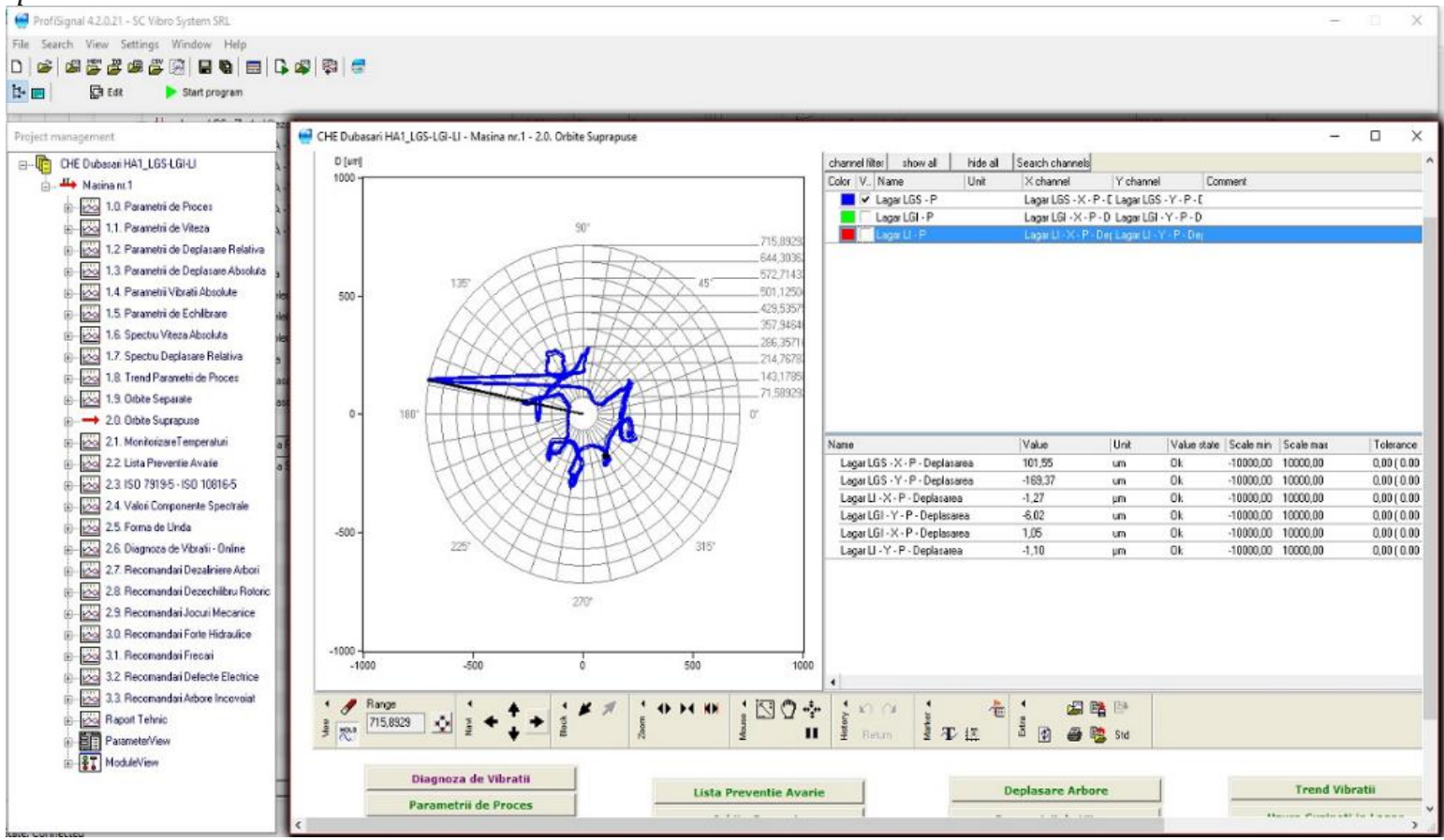

Fig. 10. A.1. LRS Bearing Orbit - Regime: 120 rpm

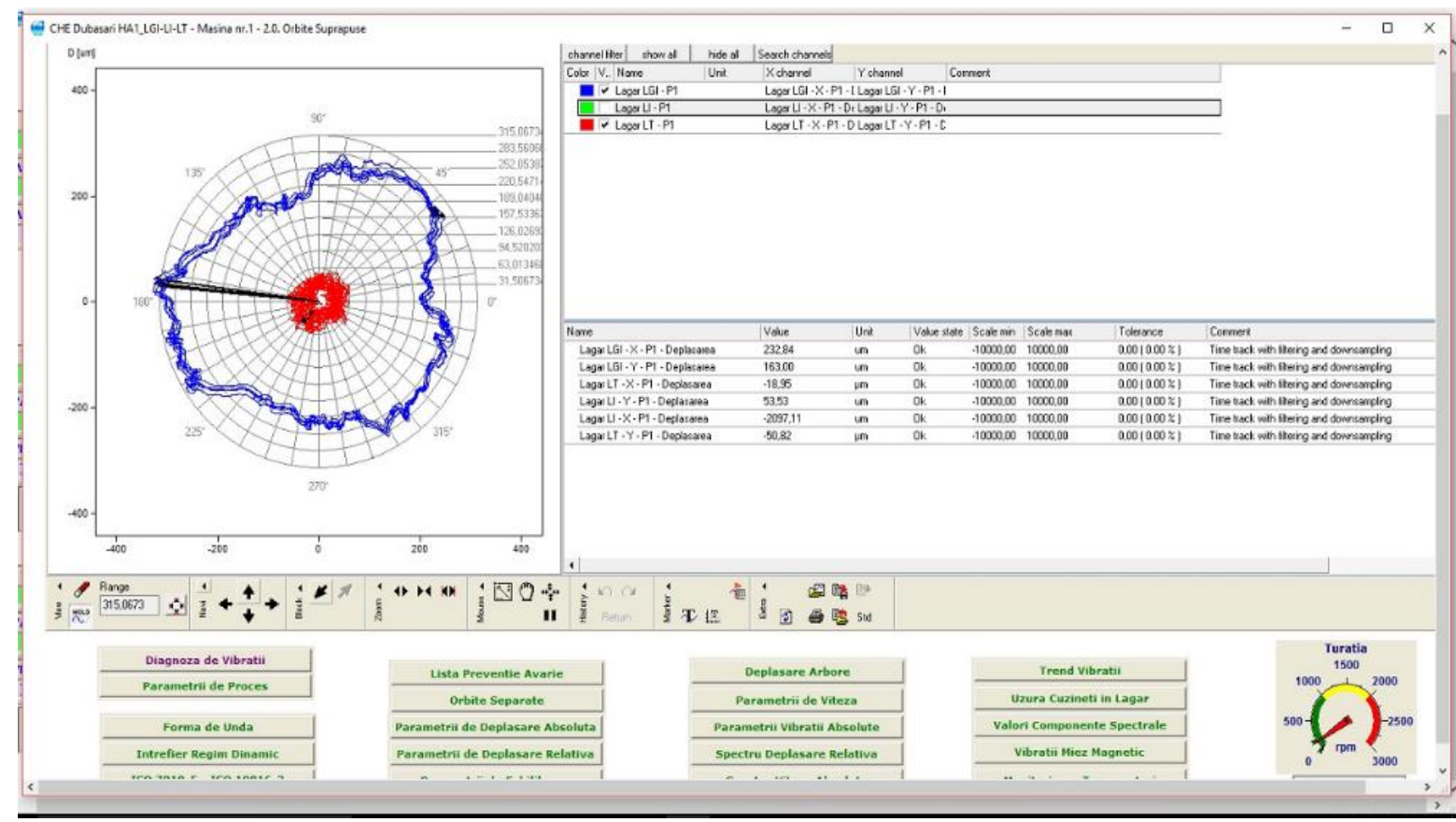

Fig. 11. A.6. LGI -LT Bearing Orbit-Regime: 120 rpm 